\title{
Penerapan Metode Sol-Gel dengan Variasi Temperatur dan Waktu Kalsinasi pada Sintesis Barium M-Heksaferit $\left(\mathrm{BaFe}_{12} \mathrm{O}_{19}\right)$
}

\author{
Idon Joni dan Darminto* \\ Jurusan Fisika, FMIPA-Institut Teknologi Sepuluh Nopember \\ Kampus ITS Sukolilo Surabaya 60111
}

\begin{abstract}
Intisari
Pada penelitian ini telah dilakukan sintesis Barium M-Heksaferit $\left(\mathrm{BaFe}_{12} \mathrm{O}_{19}\right)$ dengan metode sol-gel. Prekursor yang dihasilkan dari proses sol-gel telah dikalsinasi pada temperatur $600-1000^{\circ} \mathrm{C}$ dalam waktu 3, 4, dan 5 jam. Identifikasi fasa dengan menggunakan XRD dan software Rietica menghasilkan fraksi fasa $\mathrm{BaFe}_{12} \mathrm{O}_{19}$ tertinggi sebesar 64,9\%. Sampel serbuk yang dihasilkan mempunyai nilai magnetisasi saturasi 15,97 emu/gr, medan koersivitas 0,35 tesla dan magnetisasi remanensi 9,46 emu/gr berdasarkan hasil pengukuran dengan VSM.
\end{abstract}

\begin{abstract}
Synthesis of Barium M-Heksaferit $\left(\mathrm{BaFe}_{12} \mathrm{O}_{19}\right)$ was conducted by sol-gel method. The precursors resulted from the sol-gel process was calcinated at $600-1000^{\circ} \mathrm{C}$ for 3,4 , dan 5 hours. Phase purity examination using XRD dan Rietica software has given result $\mathrm{BaFe}_{12} \mathrm{O}_{19}$ content of $64.9 \%$. The prepared powders have the saturated magnetisation of $15.97 \mathrm{emu} / \mathrm{gr}$, coercivity of 0.35 tesla and remanent magnetisation of $9.46 \mathrm{emu} / \mathrm{gr}$ according to measurement using VSM.
\end{abstract}

KATA KUNCI: Barium M-Heksaferit $\left(\mathrm{BaFe}_{12} \mathrm{O}_{19}\right)$, sol gel, kalsinasi.

\section{PENDAHULUAN}

Oksida ferit heksagonal atau lebih dikenal dengan sebutan heksaferit adalah salah satu material ferimagnetik yang menarik. Material ini banyak dimanfaatkan secara komersial dan hingga kini masih diteliti untuk mengembangkannya baik dari segi fabrikasinya maupun penggunaannya [1]. Bariumheksagonal-ferit $\left(\mathrm{BaFe}_{12} \mathrm{O}_{19}\right)$, merupakan magnet permanen dengan magnetisasi saturasi dan medan koersivitas yang tinggi (hard magnetic), temperatur Curie dan anisotropi magnetik yang juga tinggi, serta kestabilan kimia yang baik dan tidak mudah korosi [2].

Unit sel kristal $\mathrm{BaFe}_{12} \mathrm{O}_{19}$ dapat dibagi dalam dua blok yaitu $\mathrm{S}$ dan $\mathrm{R}$. Blok $\mathrm{S}$ merupakan cubic closed packing dua lapisan oksigen yang membentuk strutur spinel dan blok $\mathrm{R}$ merupakan hexagonal closed packing dari tiga lapisan oksigen [3]. Setiap bagian $\mathrm{S}$ terdiri dari dua lapisan yang mengandung empat buah ion oksigen, dan paralel dengan bidang dasar heksagonal dengan tiga kation di antara setiap lapisan. Bagian $\mathrm{R}$ terdiri atas tiga lapis ion oksigen, yang pada lapis tengah satu ion oksigen diganti dengan ion $\mathrm{Ba}$. Dalam satu unit sel setiap bagian $\mathrm{S}$ mempunyai rumus kimia $\mathrm{Fe}_{6} \mathrm{O}_{8}$ dan setiap bagian $\mathrm{R}$ mempunyai rumus kimia $\mathrm{BaFe}_{6} \mathrm{O}_{11}$, seperti tersaji dalam

\footnotetext{
*E-MAIL: darminto@physics.its.ac.id
}

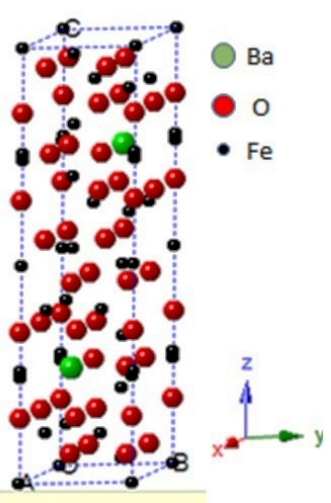

Gambar 1: Struktur kristal Barium M-Heksaferit $\mathrm{BaFe}_{12} \mathrm{O}_{19}$ [3].

Gambar 1. Rumus kimia total adalah $\mathrm{BaFe}_{12} \mathrm{O}_{19}$ [4].

Berdasarkan penelitian yang telah dilakukan sebelumnya [5], ion yang bersifat magnet dalam Barium M-Heksaferit hanyalah ion $\mathrm{Fe}^{3+}$, sedangkan $\mathrm{Ba}^{2+}$ dan $\mathrm{O}^{-2}$ mempunyai ukuran yang hampir sama, bersifat non magnetik, dan menempati close-packed. Ion $\mathrm{Fe}^{3+}$ merupakan ion magnetik dengan moment magnetik $5 \mu_{b}$ dan terletak pada tiga posisi yang berbeda dalam struktur kristal Barium M-Heksaferit. Kontribusi momen magnetik setiap posisi dalam satu molekul Barium M-Heksaferit $1 \uparrow$ trigonal bypyramidal, $7 \uparrow 2 \downarrow$ octahedral, 


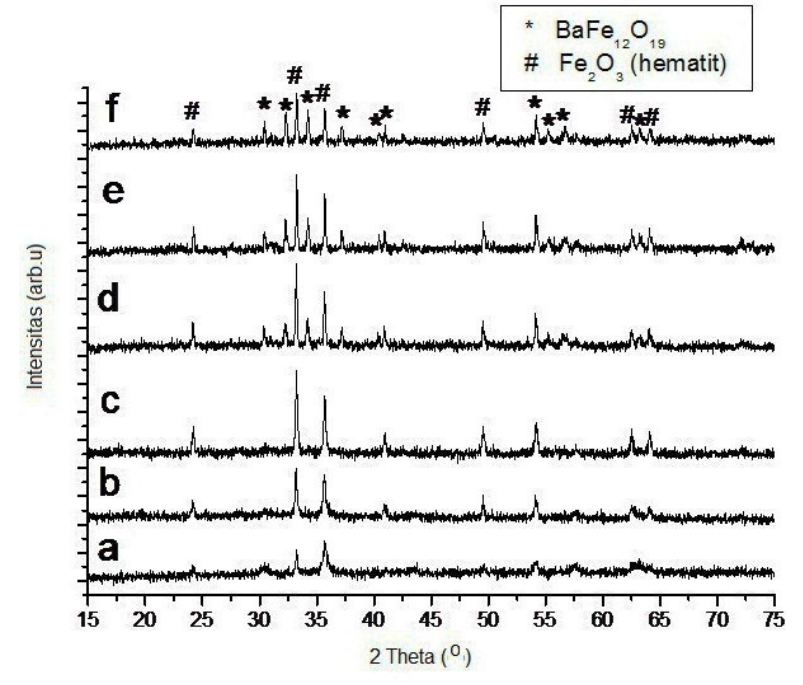

Gambar 2: Pola difraksi sampel Barium M-Heksaferit hasil kalsinasi pada (a) 600, (b) 700, (c) 800, (d) 900, (e) 1000 , dan (f) $1100^{\circ} \mathrm{C}$.

dan $2 \downarrow$ tetragonal sehingga momen magnet total dalam Barium M-Heksaferit adalah $4 \downarrow\left(20 \mu_{b}\right)$ atau $8 \uparrow\left(40 \mu_{b}\right)$ per unit sel kristal.

Metoda keramik konvensional untuk sintesis $\mathrm{BaFe}_{12} \mathrm{O}_{19}$ adalah reaksi padatan antara $\mathrm{BaCO}_{3}$ dan $\mathrm{Fe}_{2} \mathrm{O}_{3}$ pada temperatur kalsinasi yang tinggi $\left(1200^{\circ} \mathrm{C}\right)$. Sampel hasil sintesis metoda ini umumnya mempunyai kekurangan seperti ukuran butir kurang homogen dan dengan fasa takmurnian yang tinggi [5], selain memerlukan energi besar untuk pemanasannya. Berdasarkan alasan tersebut, dalam eksperimen ini dilakukan sintesis $\mathrm{BaFe}_{12} \mathrm{O}_{19}$ dengan metode sol-gel, yang secara lengkap akan dilaporkan beserta hasil karakterisasi struktur dan sifat kemagnetannya. Hal lain yang membedakan penelitian ini dengan kegiatan sintesis $\mathrm{BaFe}_{12} \mathrm{O}_{19}$ yang standar adalah digunakannya bahan dasar $\mathrm{Fe}_{2} \mathrm{O}_{3}$ dari pasir besi.

\section{METODE PENELITIAN}

Pasir besi diekstrak dan diproses secara kopresipitasi untuk menghasilkan $\mathrm{Fe}_{2} \mathrm{O}_{3} . \mathrm{H}_{2} \mathrm{O}$ sebagai bahan dasar dalam sintesis $\mathrm{BaFe}_{12} \mathrm{O}_{19}$. Selanjutnya, $\mathrm{Fe}_{2} \mathrm{O}_{3} \cdot \mathrm{H}_{2} \mathrm{O}$ dilarutkan dalam $\mathrm{HNO}_{3} 14,7 \mathrm{M}$ dan diaduk selama 45 menit pada temperatur $\pm 70^{\circ} \mathrm{C}$ sehingga diperoleh larutan ferit nitrat yang berwarna merah bening (larutan 1). Pada waktu yang sama serbuk $\mathrm{BaCO}_{3}$ dilarutkan dalam $\mathrm{HNO}_{3} 8 \mathrm{M}$ ditambah $\mathrm{H}_{2} \mathrm{O}$ dan diaduk selama 90 menit pada temperatur $\pm 70^{\circ} \mathrm{C}$, sehingga diperoleh larutan barium nitrat yang berwarna bening (laru$\tan 2$ ). Larutan 1 dan larutan 2 dicampur kemudian diaduk selama 60 menit pada temperatur $\pm 80^{\circ} \mathrm{C}$ dan ditambahkan asam asetat lalu diaduk selama 30 menit pada temperatur $80^{\circ} \mathrm{C}$. Setelah ditambahkan etilen-glikol dan diaduk selama 30 menit pada temperatur $80^{\circ} \mathrm{C}$ diperoleh sol Ba-Fe. Pengeringan sol ini pada temperatur $\pm 100^{\circ} \mathrm{C}$ selama 7 hari menghasilkan gel. Gel lalu dihaluskan dengan mortar dan diberi perlakuan panas
TABEL I: Komposisi fasa relatif hasil penghalusan (refinement) rietveld dengan menggunakan Rietica pada sampel serbuk Barium MHeksaferit. Angka dalam kurung menunjukkan ralat.

\begin{tabular}{cccccc}
\hline $\begin{array}{c}\text { Temperatur } \\
\text { kalsinasi } \\
(3 \text { jam })\end{array}$ & $\begin{array}{c}\text { Parameter } \\
\text { Kecocokan } \\
(\mathrm{GoF})\end{array}$ & \multicolumn{5}{c}{ Komposisi Fasa Relatif (\%) } \\
$\mathrm{BaFe}_{12} \mathrm{O}_{19}$ & $\alpha-\mathrm{Fe}_{2} \mathrm{O}_{3}$ & $\gamma-\mathrm{Fe}_{2} \mathrm{O}_{3}$ & $\mathrm{BaFe}_{2} \mathrm{O}_{4}$ \\
$600^{\circ} \mathrm{C}$ & 0,28 & - & $95,5(4,7)$ & $3,5(0,2)$ & $1,1(0,02)$ \\
$700^{\circ} \mathrm{C}$ & 0,52 & $25,3(2,4)$ & $74,7(3,9)$ & - & - \\
$800^{\circ} \mathrm{C}$ & 0,71 & $26,8(3,6)$ & $73,2(3,4)$ & - & - \\
$900^{\circ} \mathrm{C}$ & 0,28 & $64,9(2,7)$ & $35,0(0,8)$ & - & - \\
$1000^{\circ} \mathrm{C}$ & 0,46 & $53,3(3,2)$ & $46,5(0,1)$ & - & - \\
$1100^{\circ} \mathrm{C}$ & 0,77 & $54,9(4,2)$ & $45,0(2,9)$ & - & - \\
\hline \hline
\end{tabular}

TABEL II: Komposisi fasa relatif hasil penghalusan (refinement) rietveld dengan Menggunakan Rietica pada sampel serbuk Barium MHeksaferit pada temperatur $900^{\circ} \mathrm{C}$ dengan penahanan 3, 4, dan 5 jam.

\begin{tabular}{|c|c|c|c|}
\hline Temperatur & Parameter & \multicolumn{2}{|c|}{ K omposisi Fasa Relatif (\%) } \\
\hline kalsinasi & $\operatorname{Kecocokan}(\mathrm{GoF})$ & $\mathrm{BaFe}_{12} \mathrm{O}_{19}$ & $\alpha-\mathrm{Fe}_{2} \mathrm{O}_{3}$ \\
\hline $900^{\circ} \mathrm{C} 3 \mathrm{jam}$ & 0,28 & $64,9(2,7)$ & $35,0(0,8)$ \\
\hline $900^{\circ} \mathrm{C} 4 \mathrm{jam}$ & 0,21 & $58,9(4,8)$ & $41,1(2,2)$ \\
\hline $900^{\circ} \mathrm{C} 5 \mathrm{jam}$ & 0,25 & $59,9(3,8)$ & $40,1(3,7)$ \\
\hline
\end{tabular}

dengan variasi waktu kalsinasi 3,4, dan 5 jam pada temperatur yang juga bervariasi pada $600-1100^{\circ} \mathrm{C}$ untuk mendapatkan kristal $\mathrm{BaFe}_{12} \mathrm{O}_{19}$, yang kemudian dikarakterisasi dengan XRD dan vibrating sample magnetometer (VSM).

\section{HASIL DAN DISKUSI}

Analisis pembentukan fasa $\mathrm{BaFe}_{12} \mathrm{O}_{19}$ dilakukan dengan menggunakan XRD pada jangkauan sudut difraksi antara 15$75^{\circ}$ yang bertujuan untuk mengidentifikasi fasa-fasa yang terbentuk pada sampel. Gambar 2 menunjukkan pola difraksi sampel serbuk hasil pemanasan pada temperatur $600-1100^{\circ} \mathrm{C}$ selama 3 jam. Pada temperatur kalsinasi $600^{\circ} \mathrm{C}$ sudah teridentifikasi adanya tiga fasa yaitu $\mathrm{BaFe}_{2} \mathrm{O}_{4}, \alpha-\mathrm{Fe}_{2} \mathrm{O}_{3}$ dan $\gamma$ $\mathrm{Fe}_{2} \mathrm{O}_{3}$, sedangkan pada temperatur $700^{\circ} \mathrm{C}$ dan $800^{\circ} \mathrm{C}$ sudah mulai terjadi tranformasi fasa dengan sudah mulai teramati $\mathrm{BaFe}_{12} \mathrm{O}_{19}$ meskipun tidak dominan, atau masih lebih dominan fasa pengotor, seperti $\alpha-\mathrm{Fe}_{2} \mathrm{O}_{3}$ (hematit). Perlakuan panas pada temperatur 900,1000 , dan $1100^{\circ} \mathrm{C}$ menghasilkan fasa $\mathrm{BaFe}_{12} \mathrm{O}_{19}$ dengan kemurnian yang mencapai 64,9\% dan fasa sekunder hematit, seperti ditunjukkan pada Tabel I. Sementara itu dalam Gambar 3 disajikan spektra XRD untuk sampel yang dipanaskan pada temperatur $900^{\circ} \mathrm{C}$ selama 3, 4 dan 5 jam. Tampak dalam gambar adanya puncak struktur $\mathrm{BaFe}_{12} \mathrm{O}$ selain fasa hematit $\left(\mathrm{Fe}_{2} \mathrm{O}_{3}\right)$, dengan komposisi masing-masing seperti diberikan dalam Tabel II.

Kalsinasi digunakan untuk memberikan kesempatan kation-kation penyusun fasa saling berikatan satu sama lain membentuk kristal. Temperatur dan waktu kalsinasi merupakan faktor kunci dalam formasi fasa Barium M-Heksaferit. Faktanya, temperatur kalsinasi yang memberikan fraksi fasa $\mathrm{BaFe}_{12} \mathrm{O}_{19}$ tertinggi adalah $900^{\circ} \mathrm{C}$ untuk pemanasan selama 3 jam. Hal ini didukung oleh hasil pengukuran termal 


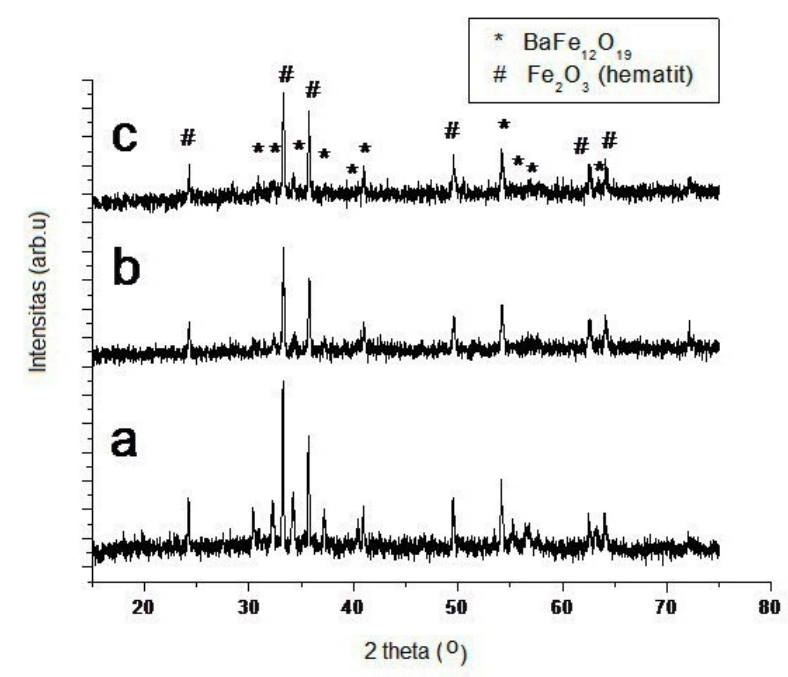

Gambar 3: Pola difraksi sampel Barium M-Heksaferit pada temperatur $900^{\circ} \mathrm{C}$ selama: (a) $3 \mathrm{jam}$, (b) 4 jam, dan (c) 5 jam.

TABEL III: Nilai medan koersivitas (Hc) dan Magnetisasi remanensi (Mr) BaM dengan variasi waktu penahan 3 jam, 4 jam, dan 5 jam pada temperatur $900^{\circ} \mathrm{C}$.

\begin{tabular}{cccc}
\hline \hline $\begin{array}{c}\text { Waktu } \\
\text { Penahanan }\end{array}$ & $\begin{array}{c}\text { Koersivitas } \\
\text { Hc }(\mathrm{T})\end{array}$ & $\begin{array}{c}\text { Magnetisasi Remanensi } \\
\text { Mr (emu/gr) }\end{array}$ & $\begin{array}{c}\text { Magnetisasi Saturasi } \\
\text { Ms (emu/gr) }\end{array}$ \\
\hline 3 jam & 0,35 & 9,46 & 15,97 \\
4 jam & 0,35 & 5,84 & 10.04 \\
5 jam & 0,36 & 5,73 & 9,99 \\
\hline \hline
\end{tabular}

dengan DTA/TG seperti dalam penelitian sebelumnya [6], bahwa ada puncak dalam kurva DTA pada temperatur yang bersangkutan, yang menandakan terjadinya transformasi fasa. Bertitik tolak dari temperatur yang memberikan fraksi fasa tertinggi ini, pemanasan pada temperatur yang sama dilakukan dalam waktu yang lebih lama (4 dan 5 jam). Ternyata, pada pemanasan yang lebih lama justru menurunkan fraksi fasa $\mathrm{BaFe}_{12} \mathrm{O}_{19}$ (Tabel II). Terjadinya dekomposisi fasa $\mathrm{BaFe}_{12} \mathrm{O}_{19}$ menjadi fasa hematit menunjukkan adanya mekanisme kompetitif dari formasi fasa, dan dalam rentang temperatur ini terlihat fasa hematit cenderung memiliki laju yang lebih tinggi untuk pemanasan yang lebih lama dari 3 jam. Dari identifikasi kandungan fasa di atas diperoleh fraksi fasa $\mathrm{BaFe}_{12} \mathrm{O}_{19}$ yang relatif tinggi sebesar 64,9\% pada temperatur $900^{\circ} \mathrm{C}$ dengan penahanan 3 jam, khususnya dibandingkan hasil penelitian lain dengan bahan dasar yang sama tetapi dengan metoda kopresipitasi, yang memperoleh $60 \%$ [6]. Di pihak lain, pemanasan selama 4 dan 5 jam menghasilkan fraksi fasa yang hampir sama.

Identifikasi untuk menentukan ukuran serbuk dan morfologi Barium M-Heksaferit dilakukan dengan menggunakan SEM-EDX dan hasilnya diberikan pada Gambar 4. Tampak dalam gambar bahwa kristal $\mathrm{BaFe}_{12} \mathrm{O}_{19}$ menunjukkan bentuknya yang tidak beraturan dan strukur yang cukup sulit untuk menentukan ukuran dan bentuk yang tepat dari partikel. Butiran partikel cenderung berpori, yang dapat terjadi karena penggunaan asam asetat sebagai katalis, dan menghasilkan

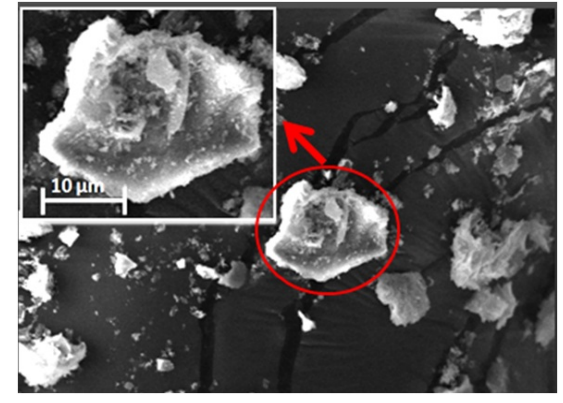

(a)

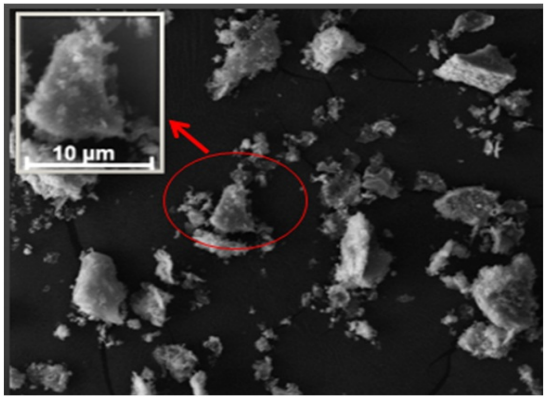

(b)

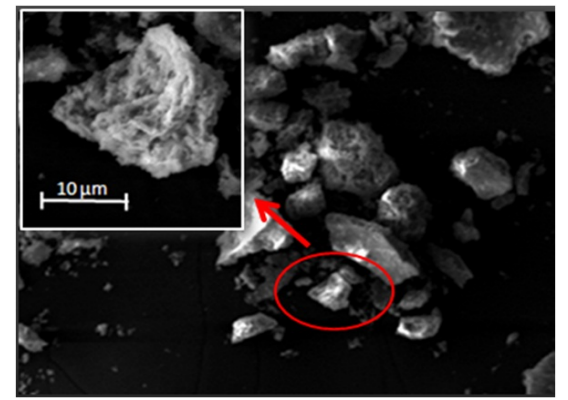

(c)

Gambar 4: Hasil SEM sampel Barium M-Heksaferit pada pemanasan $900^{\circ} \mathrm{C}$ selama: (a) 3 jam, (b) 4 jam, dan (c) 5 jam.

gas $\mathrm{CO}$ maupun $\mathrm{CO}_{2}$, ketika dipanaskan sehingga meninggalkan kekosongan (dan pori) di lokasi gas - gas tersebut terperangkap. Terkait dengan ukuran serbuk terlihat (dalam inset masing-masing gambar, diambil butiran terbesar) ukuran serbuk $\pm 25 \mu \mathrm{m}$ untuk pemanasan selama 3 jam, dan menurun dengan pemanasan yang lebih lama $\pm 9 \mu \mathrm{m}$ (pemasana selama 4 jam), dan $\pm 20 \mu \mathrm{m}$ (5 jam). Penurunan ukuran serbuk tersebut seiring dengan penuruan fraksi fasa $\mathrm{BiFe}_{12} \mathrm{O}_{16}$ dalam Tabel II, yang memperkuat terjadinya dekomposisi fasa. Sedemikian jauh dari foto SEM dalam Gambar 4, masih cukup sulit mengamati morfologi butiran partikel, karena tampak butiran masih "belum bersih".

Sifat kemagnetan sampel diperoleh dari pengukuran menggunakan VSM yang bertujuan untuk mengetahui kurva histerisis guna memperkirakan besaran kemagnetan, seperti magnetisasi saturasi $\left(\mathrm{M}_{s}\right)$, magnetisasi remanen $\left(\mathrm{M}_{r}\right)$, dan koersifitas $\left(\mathrm{H}_{c}\right)$. Gambar 5 menunjukkan kurva histerisis magnetik dari ketiga sampel yang bersesuai dengan Tabel II, dan besaran magnetik yang dihasilkan dirinci dalam Tabel III. Terli- 


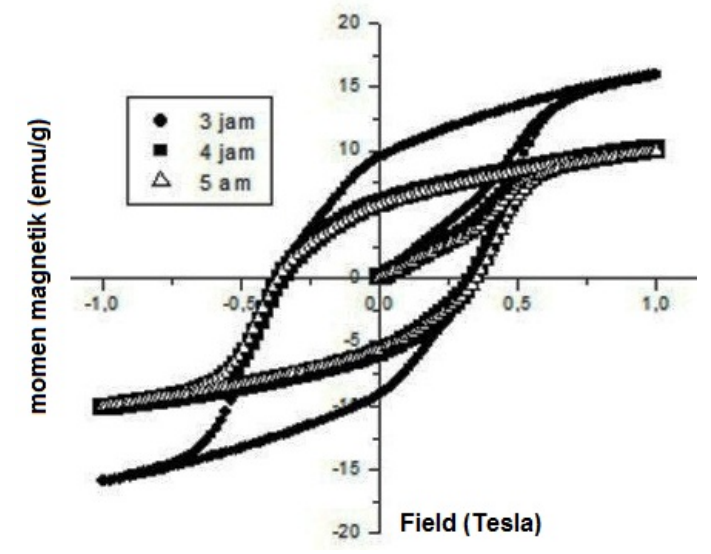

Gambar 5: Kurva Histerisis sampel Barium M-Heksaferit hasil kalsinasi pada temperatur $900^{\circ} \mathrm{C}$ selama 3,4 dan 5 jam.

hat dalam Tabel III bahwa besaran kemagnetan (terutama $\mathrm{Mr}$ dan Ms) dengan nilai terbesar dicapai oleh sampel hasil pemanasan selama 3 jam yang memiliki fraksi fasa $\mathrm{BaFe}_{12} \mathrm{O}_{19}$ tertinggi. Di pihak lain, dengan fraksi fasa yang hampir sama, sampel dengan pemanasan selama 4 dan 5 jam memberikan nilai besaran magnetik yang hampir sama. Hal ini menunjukkan bahwa kontribusi sifat magnet yang dominan berasal dari fasa $\mathrm{BaFe}_{12} \mathrm{O}_{19}$, sementara fasa hematit berperan sangat lemah dalam kemagnetan seperti telah banyak diketahui.

\section{SIMPULAN}

Metode sol gel telah mampu menghasilkan serbuk Barium M-Heksaferit dengan kemurnian yang dapat dibandingkan dengan metode kopresipitasi. Dalam rentang eksperimen ini, fraksi fasa $\mathrm{BaFe}_{12} \mathrm{O}_{19}$ tertinggi dicapai oleh sampel yang mengalami kalsinasi pada temperatur $900^{\circ} \mathrm{C}$ selama 3 jam, dengan fasa impuritas $\mathrm{Fe}_{2} \mathrm{O}_{3}$. Sifat magnetik dari sampel bergantung pada nilai kandungan fasa $\mathrm{BaFe}_{12} \mathrm{O}_{19}$.
[1] M.C. Dimri, et al., Ceramics International 30, 1623-1626 (2004).

[2] A. Mali, and A. Ataie, J. Alloys and Compounds, 399, 245-250 (2005).

[3] G. Albanese, J. de Physique, 38, C1-85 (1977).

[4] I. Novrita, dan Dedi, Pembuatan Barium Heksaferit Anisotropi, Indonesian Journal of material of science, (2003).
[5] Mozaffari, et al., J. Magnetism and Magnetic Materials, 321, 1285-1289 (2009).

[6] N. Afidah, Karakterisasi sifat magnetik dan serapan gelombang mikro barium M-Heksaferit $\mathrm{BaFe}_{12} \mathrm{O}_{19}$, Tesis Program S2, Jurusan Fisika, FMIPA ITS, 2011. 